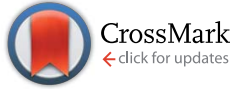

Cite this: RSC Adv., 2016, 6, 60815
Received 27th February 2016

Accepted 12th June 2016

DOI: 10.1039/c6ra05211h

www.rsc.org/advances

\section{Microwave regeneration of spent activated carbon for the treatment of ester-containing wastewater $\dagger$}

\begin{abstract}
Tianlong Zheng, ${ }^{\text {ab }}$ Qunhui Wang, ${ }^{\text {*ac }}$ Zhining Shi, ${ }^{d}$ Zhihui Zhang ${ }^{a}$ and Yuhui Ma ${ }^{\text {ae }}$
In this study, an integrated granular activated carbon (GAC) adsorption/microwave (MW) irradiation process was used for the treatment of ester-containing wastewater from a lithium-ion battery (LIB) factory. Firstly, ester-containing organic matter was adsorbed onto GAC, then the pollutants were decomposed. The GAC was then regenerated by MW irradiation. The efficacy of this procedure was analyzed by determining adsorption effectiveness, adsorption kinetics and the textural properties of GAC in successive GAC adsorption/MW cycles. The mechanism of MW regeneration was investigated by Fourier transform infrared spectroscopy (FTIR) and thermogravimetric (TG) analysis. The results show that the adsorption isotherms and kinetics for the adsorption of ester contaminants are in accordance with Langmuir isotherm and pseudo second-order kinetic models. It was also found that though the adsorption rate constant $\left(k_{2}\right)$ of GAC increased with the adsorption/MW regeneration cycles, the adsorption capacity $\left(q_{\mathrm{m}}\right)$ decreased where the $q_{m}$ of GAC at the 5 th regeneration cycle had a $20.4 \%$ reduction in comparison to the determined original GAC, which could be explained by changes in the GAC's textural properties. The GAC adsorption/MW process mainly occurred at the peak of $1117 \mathrm{~cm}^{-1}$ by FTIR. Through TG and differential thermogravimetric (DTG) analyses, the weight loss of saturated GAC took place between $120^{\circ} \mathrm{C}$ and $260^{\circ} \mathrm{C}$, caused by the decomposition of ester organic molecules.
\end{abstract}

\section{Introduction}

Lithium-ion batteries (LIBs), which are light weight, energy dense, and have a long storage life, have been increasingly produced since industrialization in the 1990s, largely for applications in the portable electronics industry. ${ }^{\mathbf{1 , 2}}$ The disposal of spent LIBs has attracted much attention from environmental scientists $^{3,4}$ due to the latent environmental risks caused by the use of a wide variety of complex solvents and heavy metals. ${ }^{5}$ In the past decades, research has focused on the recovery of valuable metals from spent LIBs $^{6-8}$ and on the removal of heavy metals from landfills containing spent LIBs, as heavy metals have been known to leach into surrounding soils. ${ }^{9-11}$ However, the reclamation of wastewater generated by the LIB

${ }^{a}$ Department of Environmental Engineering, University of Science and Technology Beijing, 30 Xueyuan Road, Haidian District, Beijing 100083, China. E-mail: wangqh59@sina.com; Fax: +86-010-62332778; Tel: +86-010-62332778

${ }^{b}$ Research Center for Eco-Environmental Sciences, Chinese Academy of Sciences, Beijing 100085, China

${ }^{c}$ Beijing Key Laboratory of Resource-oriented Treatment of Industrial Pollutants, University of Science and Technology Beijing, 30 Xueyuan Road, Haidian District, Beijing 100083, China

${ }^{d}$ School of Earth and Environmental Sciences, The University of Adelaide, South Australia 5005, Australia

${ }^{e}$ Institute of Tianjin Seawater Desalination and Multi-purpose Utilization, State Ocean Administration (SOA), Tianjin 300192, China

$\dagger$ Electronic supplementary information (ESI) available. See DOI: 10.1039/c6ra05211h manufacturing processes has not yet been investigated. LIB manufacturing wastewater contains a significant amount of organics and inorganics such as dimethyl carbonate (DMC), carbonic acid ethyl methylester (CEM), diethyl carbonate (DC), ethylene carbonate (EC), $N$-methylpyrrolidone (NMP) and lithium hexafluoro phosphate $\left(\mathrm{LiPF}_{6}\right)$. Biodegradation is not an efficient treatment of the wastewater as it contains complicated components with high levels of chemical oxygen demand (COD) and low levels of biodegradability. ${ }^{12}$

Activated carbon (AC) adsorption may be one of the most effective technologies for the pretreatment of highly concentrated and refractory organic wastewater. ${ }^{13,14}$ The application of AC adsorption allow the effect of toxic pollutants on microbes to be alleviated, which is conducive to a stable and cost effective treatment process. ${ }^{\mathbf{1 4}}$ The economics of the adsorption process depends on the potential reuse of AC. There are several wellestablished methods for the regeneration of exhausted AC, including thermal, chemical and biological regeneration. ${ }^{\mathbf{1 5}}$ Thermal regeneration is the most widely used regeneration technology, however, it requires an extremely high temperature environment (above $1100 \mathrm{~K}$ ) and its application is limited due to the significant energy demand. ${ }^{\mathbf{1 6}}$ Chemical regeneration involves desorption of adsorbates with specific solvents or by decomposition of adsorbed species using oxidizing chemical agents under subcritical/supercritical conditions. ${ }^{15,17}$ The requirement of further purification and the necessity of harmful solvents increases disposal costs. ${ }^{18}$ As a result of the long 
reaction time and the limitations of biodegradable adsorbed substances, no efficient biological regeneration protocol has yet been found. ${ }^{15,19}$

Microwave (MW) regeneration is a promising method of AC regeneration because of its short regeneration time, high regeneration efficiency, less regeneration loss and significant energy savings. ${ }^{20-22}$ Presently, new-type carbon materials called magnetoresistive polyaniline-magnetite nanocomposites have been explored with microwave absorption applications, which possess stabilized magnetic properties, oxidative resistance and indissolvable potential under acidic condition. ${ }^{23,24}$ However, the adsorption and regeneration mechanism of the MW regeneration for spent AC needs to be comprehensively understood under different reaction conditions. Ania et al. ${ }^{25}$ reported the regeneration of AC spent with salicylic acid having regeneration efficiencies of up to $99 \%$ after six cycles with MW irradiation at $2450 \mathrm{MHz}$. Liu et $a l .{ }^{26}$ regenerated GAC that had been spent with 2,4,5-trichlorobiphenyl in a simulated soil-washing solution in a quartz reactor with $2450 \mathrm{MHz} \mathrm{MW}$ irradiation for $5 \mathrm{~min}$, with a regeneration yield after five adsorption/regeneration cycles of up to $163 \%$. Mao et al. ${ }^{27}$ also examined the microwave-assistant irradiation restored the original adsorption capacity of the spent activated carbon prepared with pine and wheat activated carbon, when the microwave regeneration was conducted at a constant power of $600 \mathrm{~W}$ for irradiation times of $3 \mathrm{~min}$ (toluene) and $1 \mathrm{~min}$ (acetone), the results showed that the regeneration efficiencies after the initial cycle of microwave irradiation were $97.0-98.4 \%$ during the five adsorption/ regeneration cycles. Deng et $a .^{28}$ showed that the prepared functional fibrous fibers still retained more than $85 \%$ of the original adsorption capacity for the heavy metal ions from wastewater, which indicated that there was no appreciable loss in capacities during the five MW regeneration cycles. Liu et al. ${ }^{29}$ derived that the regenerated efficiency of exhausted GAC was $97.6 \%$ of its original adsorption when the microwave power, radiation time and the GAC amount were $400 \mathrm{~W}, 3 \mathrm{~min}$, and $10 \mathrm{~g}$ respectively. The regenerated efficiency maintained a stable performance in the first few repetitions, but a decrease was observed after further repetitions. Despite the availability of several studies, the mechanisms of successive AC adsorption/ MW regeneration had never being observed during the estercontaining wastewater treatment. In our previous study, ${ }^{12}$ optimal parameters for GAC adsorption and MW regeneration were determined for the pretreatment of ester-containing wastewater from a LIB factory. However, the inherent mechanism including adsorption equilibrium isotherms, adsorption kinetics, and MW regeneration were not determined.

In this study, a GAC adsorption/MW irradiation process was used in the treatment of ester-containing wastewater from a LIB factory. Adsorption efficiency, regeneration efficiency, and the regeneration loss rate were analyzed in successive adsorption/ MW regeneration cycles under optimal operation conditions. The adsorption equilibrium isotherms and adsorption kinetics of the GAC were also investigated. The mechanisms of MW regeneration were also explored, based on Brunauer-EmmettTeller (BET) theory, Fourier transform infrared spectroscopy (FTIR), and thermogravimetric (TG) analysis.

\section{Materials and methods}

\subsection{Wastewater}

The experimental wastewater was ester-containing wastewater generated by a LIB factory in Northern China. The wastewater was a mixture of the wastewater from the cleaning of the surface of LIBs after the secondary seal producing processes and the condensate water of a vacuum pump involved in the liquid injection process. The wastewater was stored at $4{ }^{\circ} \mathrm{C}$. The physical and chemical properties of the wastewater are shown in Table 1. This wastewater is characterized by high levels of chemical oxygen demand (COD) and low biodegradability, and contains ester organic pollutants such as dimethyl carbonate, diethyl carbonate, and methyl ethyl carbonate. The main composition of pollutants in the ester-containing wastewater is shown in Table S1.†

\subsection{Experimental procedure}

2.2.1 GAC adsorption. Treatment of ester-containing wastewater with the activated carbon adsorption method was investigated. $100 \mathrm{~mL}$ of wastewater and the original GAC (OAC) were added into a $250 \mathrm{~mL}$ Erlenmeyer flask which was placed on a shaking table. The rotation speed and temperature were 150 $\mathrm{rpm}$ and $20{ }^{\circ} \mathrm{C}$ respectively. This adsorption experiment was conducted under conditions of $\mathrm{pH} 3.0-5.0$ and a GAC dosage of $10 \mathrm{~g} \mathrm{~L}^{-1}$. $^{12}$

2.2.2 MW regeneration. The saturated GAC (SAC) was regenerated by MW. Under the conditions of a MW power of 420 $\mathrm{W}$ and irradiation time of 6 min per cycle, ${ }^{12}$ the regeneration efficiency and regeneration loss of the regeneration cycles were investigated.

The regeneration efficiency $\left(R_{\mathrm{E}}\right)$ and regeneration loss $\left(R_{\mathrm{S}}\right)$ were calculated with the following equations:

$$
\begin{gathered}
R_{\mathrm{E}}=\frac{\mathrm{COD}_{\mathrm{cr}} \text { removal of } \mathrm{OAC}(\%)}{\mathrm{COD}_{\mathrm{cr}} \text { removal of } \mathrm{RAC}(\%)} \times 100 \% \\
R_{\mathrm{S}}=\frac{\text { OAC weight }(\mathrm{g})-\mathrm{RAC} \text { weight }(\mathrm{g})}{\text { OAC weight }(\mathrm{g})} \times 100 \%
\end{gathered}
$$

where OAC represents the original granular activated carbon before adsorption and RAC is the regenerated GAC that was the product of MW regeneration of SAC.

\subsection{Analytical methods}

Most of the wastewater quality parameters were measured according to The Water and Wastewater Monitoring and Analysis Method (4th Edition). ${ }^{30}$ In addition, $\mathrm{COD}_{\mathrm{cr}}, \mathrm{BOD}_{5}$, and TOC were respectively measured by a COD rapid digestion apparatus (DIS-1A, Shenzhen Changhong Instrument, Co., Ltd., China), OxiTop system (OxiTop, WTW, Germany), and vario TOC analyzer (vario TOC, Elementar, Germany). The $\mathrm{pH}$ was determined with an automatic potentiometric titrator meter (ZD-2, LEICI, China) at $20^{\circ} \mathrm{C}$.

The surface area and pore characteristics of GAC were analyzed using a gas adsorption apparatus (QuadraSorb SI, Quantachrome Instruments, USA). A BET equation was used to 
Table 1 Characteristics of the ester-containing LIB factory wastewater. Data generated from 107 samples of $\mathrm{COD}_{\mathrm{cr}}$ and $\mathrm{pH}$ and 53 samples of $\mathrm{BOD}_{5}, \mathrm{NH}_{3}-\mathrm{N}$ and $\mathrm{BOD}_{5} / \mathrm{COD}_{\mathrm{cr}}{ }^{a}$

\begin{tabular}{lllll}
\hline Parameter & $\mathrm{COD}_{\mathrm{cr}}\left(\mathrm{mg} \mathrm{L}^{-1}\right)$ & $\mathrm{BOD}_{5}\left(\mathrm{mg} \mathrm{L}^{-1}\right)$ & $\mathrm{NH}_{3}-\mathrm{N}\left(\mathrm{mg} \mathrm{L}^{-1}\right)$ & $\mathrm{BOD}_{5} / \mathrm{COD}_{\mathrm{cr}}$ \\
\hline Range of values & $1800-3000$ & $120-360$ & $0.3-1.0$ & $0.05-0.12$ \\
Mean \pm S.D. & $2316 \pm 130$ & $147 \pm 48$ & $0.48 \pm 0.08$ & $0.06 \pm 0.008$
\end{tabular}

${ }^{a}$ S.D. is the abbreviation of standard deviation.

calculate the total surface area and average pore diameter. The total pore volume was calculated from a single $\mathrm{N}_{2}$ adsorbance point at a relative pressure of 0.99 . Density functional theory (DFT) was used to analyze the successive pore size distribution curve from micropores to mesopores. The micropore and mesopore size distributions were deduced using the HorvathKawazoe (HK) and Barrett-Joyner-Halenda (BJH) methods.

The chemical functional groups in the samples were investigated by FTIR (Nicolet 6700, Thermo Fisher Scientific, USA). Thin disc samples with a diameter of approximately $10 \mathrm{~mm}$ and a thickness of $1 \mathrm{~mm}$ were made from a homogeneous mixture of GAC samples and a certain amount of potassium bromate $(\mathrm{KBr})$. Each sample was then scanned at wavenumbers from a range of 4000 to $400 \mathrm{~cm}^{-1}$. The quantities of surface functional groups were measured with the Boehm iodometric method. ${ }^{31}$

TG and derivative thermogravimetric (DTG) analysis was carried out with a thermogravimetric analyzer (TG/DTA6300, SEIKO, Japan). To investigate the pyrolysis behaviors of the original, saturated, and regenerated activated carbon, approximately 5 to $10 \mathrm{mg}$ of each sample was pyrolysed under $200 \mathrm{~cm}^{3}$ $\min ^{-1} \mathrm{~N}_{2}$ (99.995\%) flow at a heating rate of $10^{\circ} \mathrm{C} \mathrm{min}^{-1}$ from room temperature to $900{ }^{\circ} \mathrm{C}$. Before the TG-DTG analysis, the saturated GAC was dried in an oven at $80^{\circ} \mathrm{C}$ for $3 \mathrm{~h}$.

$\mathrm{COD}_{\mathrm{cr}}$ etc. means were calculated from three independent runs of the reactor, with values given as mean \pm standard deviation throughout the text.

\subsection{Adsorption studies}

2.4.1 Adsorption isotherms. Equilibrium sorption studies were conducted in a set of $250 \mathrm{~mL}$ Erlenmeyer flasks each containing $100 \mathrm{~mL}$ ester-containing wastewater and 0.2, 0.4, 0.6,
$0.8,1.0,1.5,2.0,3.0$, and $5.0 \mathrm{~g}$ OAC or RAC with a corresponding initial AC amount $\left(2,4,6,8,10,15,20,30\right.$ and $50 \mathrm{~g} \mathrm{~L}^{-1}$, respectively). The flasks were agitated in a shaker at $150 \mathrm{rpm}$ and $20{ }^{\circ} \mathrm{C}$ for $2 \mathrm{~h}$ to reach equilibrium. Samples were taken at regular time intervals and the concentrations of $\mathrm{COD}_{\mathrm{cr}}$ were measured. The $\mathrm{COD}_{\mathrm{cr}}$ uptake per unit mass of adsorbent at equilibrium, $q_{\mathrm{e}}\left(\mathrm{mg} \mathrm{g}^{-1}\right)$, was calculated by eqn (3):

$$
q_{\mathrm{e}}=\frac{\left(C_{0}-C_{\mathrm{e}}\right) V}{m}
$$

where $C_{0}$ and $C_{\mathrm{e}}\left(\mathrm{mg} \mathrm{L}^{-1}\right)$ are the initial and equilibrium liquidphase concentrations of $\mathrm{COD}_{\mathrm{cr}}, V(\mathrm{~L})$ is the volume of the wastewater, and $m(\mathrm{~g})$ is the mass of OAC or RAC used. The equilibrium data were modeled using the Langmuir, Freundlich and Temkin isotherm models, and the model equations are shown in Table 2.32,33

2.4.2 Adsorption kinetics. The experiment was performed at $20^{\circ} \mathrm{C}$ using $1.0 \mathrm{~g}$ of OAC or RAC with $100 \mathrm{~mL}$ of wastewater in a $250 \mathrm{~mL}$ Erlenmeyer flask. The amount of $\mathrm{COD}_{\mathrm{cr}}$ adsorbed by carbon at time $t, q_{t}\left(\mathrm{mg} \mathrm{g}^{-1}\right)$, was calculated by eqn (4):

$$
q_{t}=\frac{\left(C_{0}-C_{t}\right) V}{m}
$$

where $C_{t}\left(\mathrm{mg} \mathrm{L}^{-1}\right)$ is the liquid-phase concentration of $\mathrm{COD}_{\mathrm{cr}}$ at time $t$. Three widely used kinetic models, including pseudofirst-order, pseudo-second-order and Elovich kinetic models (Table 3), ${ }^{34}$ were used to characterize the adsorption process of GAC during the adsorption/MW irradiation process.

2.4.3 Adsorption mechanism. The adsorption process is not only confined to interactions between solutes on the surface of the adsorbents but also the mechanisms by which solutes diffuse into the pores of the adsorbent. In order to examine the

Table 2 Linear and non-linear forms of Langmuir, Freundlich, and Temkin isotherm models ${ }^{a}$

\begin{tabular}{llll}
\hline Model & Non-linear form & Linear form & Plot \\
\hline Langmuir & $q_{\mathrm{e}}=\frac{q_{\mathrm{m}} K_{\mathrm{L}} C_{\mathrm{e}}}{1+K_{\mathrm{L}} C_{\mathrm{e}}}$ & $\frac{C_{\mathrm{e}}}{q_{\mathrm{e}}}=\frac{1}{q_{\mathrm{m}}} C_{\mathrm{e}}+\frac{1}{K_{\mathrm{L}} q_{\mathrm{m}}}$ & $\frac{C_{\mathrm{e}}}{q_{\mathrm{e}}}$ versus $_{\mathrm{e}}$ \\
Freundlich & $q_{\mathrm{e}}=K_{\mathrm{F}} C_{\mathrm{e}}^{1 / n}$ & $\ln q_{\mathrm{e}}=\frac{1}{n} \ln C_{\mathrm{e}}+\ln K_{\mathrm{F}}$ & $q_{\mathrm{e}}$ versus $\ln C_{\mathrm{e}}$ \\
Temkin & $q_{\mathrm{e}}=B \ln \left(K_{\mathrm{T}} C_{\mathrm{e}}\right)$ & $q_{\mathrm{e}}=\frac{R T}{b} \ln C_{\mathrm{e}}+\frac{R T}{b} \ln K_{\mathrm{T}}$ &
\end{tabular}

${ }^{a} q_{\mathrm{m}}\left(\mathrm{mg} \mathrm{g}^{-1}\right)$ is the maximum monolayer adsorption capacity of the sorbent, $K_{\mathrm{L}}\left(\mathrm{L} \mathrm{mg}^{-1}\right)$ is the Langmuir constant related to the free energy of the sorption, and $K_{\mathrm{F}}\left(\mathrm{mg} \mathrm{g}^{-1}\right)\left(\mathrm{L} \mathrm{mg}^{-1}\right)^{1 / n}$ and $1 / n$ are the Freundlich adsorption constant and a measure of adsorption intensity; $K_{\mathrm{T}}\left(\mathrm{L} \mathrm{mg}{ }^{-1}\right)$ is the Temkin equilibrium binding constant, and $B=R T / b$, with $R\left(8.314 \mathrm{~J} \mathrm{~mol}^{-1} \mathrm{~K}^{-1}\right), T(\mathrm{~K})$, and $b\left(\mathrm{~J} \mathrm{~mol}{ }^{-1}\right)$, are the Temkin constant that refer to the gas constant, absolute temperature, and heat of sorption, respectively. 
Table 3 Linear and non-linear forms of pseudo-first-order, pseudo-second-order and Elovich kinetic models ${ }^{a}$

\begin{tabular}{llll}
\hline Model & Non-linear form & Linear form & Plot \\
\hline Pseudo-first-order & $q_{t}=q_{\mathrm{e}}\left[1-\exp \left(-k_{1} t\right)\right]$ & $\ln \left(q_{\mathrm{e}}-q_{t}\right)=\ln q_{\mathrm{e}}-k_{1} t$ & $\ln \left(q_{\mathrm{e}}-q_{t}\right)$ versus $t$ \\
Pseudo-second-order & $q_{t}=\frac{k_{2} q_{\mathrm{e}}^{2} t}{1+k_{2} q_{\mathrm{e}} t}$ & $\frac{t}{q_{t}}=\frac{1}{q_{\mathrm{e}}} t+\frac{1}{k_{2} q_{\mathrm{e}}{ }^{2}}$ & $\frac{t}{q_{t}}$ versus $t$ \\
Elovich & $q_{t}=b \ln (a b t)$ & $q_{t}=\frac{1}{b} \ln t+\frac{1}{b} \ln (a b)$ & $q_{t}$ versus $\ln t$
\end{tabular}

${ }^{a} k_{1}\left(\mathrm{~min}^{-1}\right), k_{2}\left(\mathrm{~g} \mathrm{mg}^{-1} \mathrm{~min}^{-1}\right)$ are the adsorption rate constants of the pseudo-first-order equation and pseudo-second-order equations, respectively. $a\left(\mathrm{mg} \mathrm{g}^{-1} \mathrm{~min}^{-1}\right)$ is the initial sorption rate and $b\left(\mathrm{~g} \mathrm{mg}^{-1}\right)$ is related to the extent of surface coverage and activation energy for chemisorption. The value of $(1 / b)$ is indicative of the available number of sites for adsorption while $(1 / b) \ln (a b)$ is the adsorption quantity when $\ln t=0$.

diffusion mechanism of the adsorption process, the Weber and Morris intraparticle diffusion model (IPD) ${ }^{35}$ was applied to analyze the kinetic results:

$$
q_{t}=k_{\mathrm{di}} t^{0.5}+C_{\mathrm{di}}
$$

where $k_{\mathrm{di}}\left(\mathrm{g} \mathrm{mg}^{-1} \mathrm{~min}^{-0.5}\right)$ is the diffusion rate constant and $C_{\mathrm{i}}$ reflects the boundary layer effect. If intraparticle diffusion is involved, the plot $q_{t}$ versus $t^{0.5}$ gives a straight line with slope, $k_{\mathrm{di}}$ and intercept, $C_{\mathrm{di}}$. If intraparticle diffusion is the only ratelimiting step, the plot passes through the origin. Alternatively, both external diffusion and intraparticle diffusion contribute to the adsorption process when the straight line deviates from the origin. The larger $C_{\mathrm{di}}$ indicates the greater effect of the boundary layer on diffusion.

\section{Results and discussion}

\subsection{The GAC adsorption under various MW regeneration cycles}

3.1.1 GAC adsorption and MW regeneration effectiveness. Variation in adsorption efficiency, regeneration efficiency, and the regeneration loss rate were investigated under the optimal operation conditions (shown in Section 2.2), with the results shown in Fig. 1.
Fig. 1a shows a reduction in the $\mathrm{COD}_{\mathrm{cr}}$ of the wastewater during the GAC adsorption for $30 \mathrm{~min}$, and then a stable level for the remaining $90 \mathrm{~min}$. The $\mathrm{COD}_{\mathrm{cr}}$ removal efficiency of GAC was $67.5 \%$ at the adsorption time of $30 \mathrm{~min}$, corresponding to an improved biodegradability from 0.06 to 0.25 . The $\mathrm{COD}_{\mathrm{cr}}$ removal rate decreased in further MW regeneration cycles, which might have been caused by a change in the textural structure of GAC, i.e. the oxidation of interior specific area and the obstruction of mesopores. When the SAC was regenerated at the first cycle, the $R_{\mathrm{E}}$ was $98.7 \%$, corresponding to a $5.2 \% R_{\mathrm{S}}$, which suggests that MW is efficient in the regeneration of saturated activated carbon (shown in Fig. 1b). After $5 \mathrm{MW}$ regeneration cycles, the $R_{\mathrm{E}}$ was still up to $76.9 \%$, though the $R_{\mathrm{S}}$ value was slightly high (14.7\%). Therefore, the weight loss of the SAC during MW regeneration should be discussed. In the current study, the $R_{\mathrm{S}}$ value over five regeneration cycles were successively 5.2, 9.9, 12.1, 12.9 and $14.7 \%$ respectively. It could be because the high temperature and certain oxygen containing reaction environments during MW regeneration led to a weight loss for the SAC. Furthermore, the textural properties were possibly changed (shown in Fig. 5a) at high temperature, resulting in a decrease in the mechanical properties, which brought about additional weight loss by abrasion. However, the regeneration loss was not unfeasible based on laboratory scale
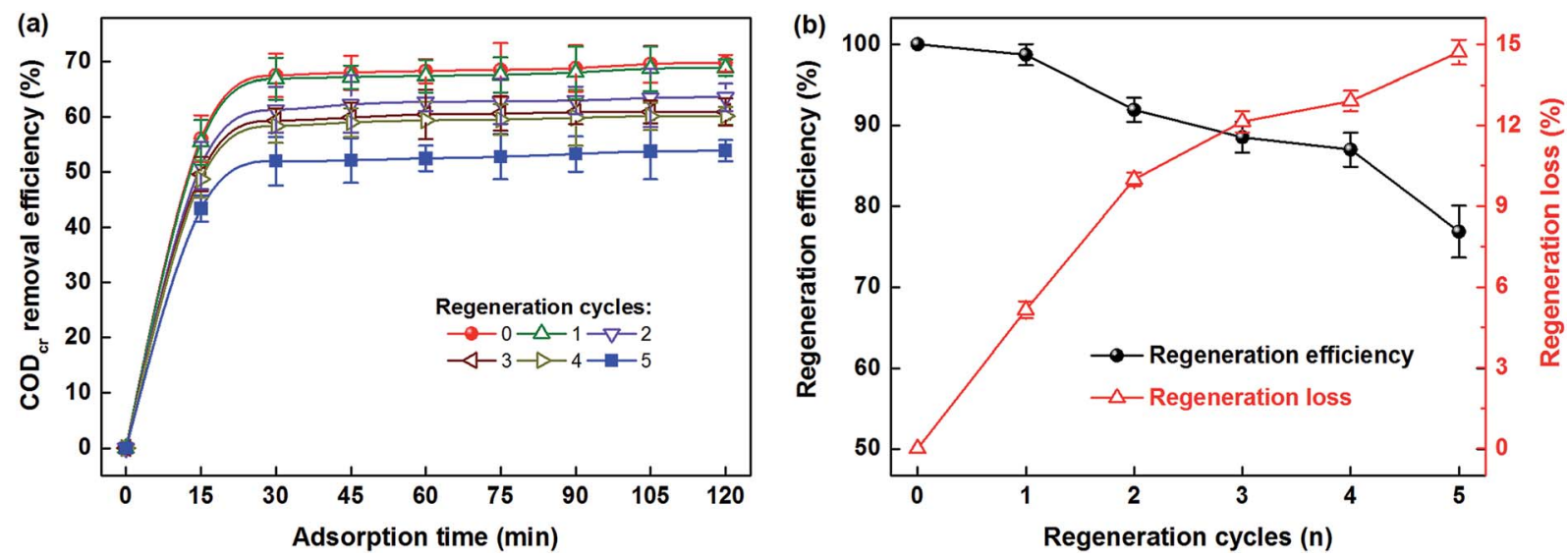

Fig. 1 (a) The variation of $C O D_{c r}$ removal with adsorption time and the variation of $\mathrm{BOD}_{5} / \mathrm{COD}_{\mathrm{cr}}$ with GAC adsorption under different regeneration cycles; (b) the variation of regeneration efficiency and regeneration loss with the MW regeneration cycles. Error bars represent standard deviation of three samples each from an independent run of the reactor. 
testing results, suggesting that the MW regeneration process is still could be economically viable during the scale-up of MW regeneration in the near future.

3.1.2 Adsorption equilibrium isotherms. Fig. 2 shows that the regeneration process has a small effect on the nature of adsorption, with little difference in adsorption isotherm shape between 5th-RAC and OAC. With the analysis of different adsorption isotherms including Langmuir isotherm, Freundlich isotherm, and Temkin isotherm, isotherms of 5th-RAC and OAC exhibited very good fits with the Langmuir isotherm. The Langmuir adsorption isotherm describes the gas-solid-phase adsorption onto activated carbon, which was always applied to quantify and contrast the performance of different biosorbents. ${ }^{36}$ In its derivation, the Langmuir isotherm refers to homogeneous adsorption, where each molecule possesses constant enthalpies and sorption activation energy (all sites possess equal affinity for the adsorbate), with no transmigration of the adsorbate in the plane of the surface. ${ }^{37}$ According to the slope and intercept of the Langmuir equation (inset of Fig. 2b), the Langmuir constants of OAC $\left(K_{\mathrm{L} 1}\right)$ and 5th-RAC $\left(K_{\mathrm{L} 2}\right)$ are $0.013 \mathrm{~L} \mathrm{mg}^{-1}$ and $0.0027 \mathrm{~L} \mathrm{mg}^{-1}$. Therefore, a dimensionless constant, commonly known as a separation factor $\left(R_{\mathrm{L}}\right)$ defined by Weber and Chakravorti, ${ }^{38}$ can be represented as:

$$
R_{\mathrm{L}}=\frac{1}{1+K_{\mathrm{L}} C_{0}}
$$

where $K_{\mathrm{L}}\left(\mathrm{L} \mathrm{mg}^{-1}\right)$ refers to the Langmuir constant and $C_{0}$ is denoted to be the adsorbate initial concentration $\left(\mathrm{mg} \mathrm{L}^{-1}\right)$. In this study, a lower $R_{\mathrm{L}}$ value reflects that adsorption is favourable. The $R_{\mathrm{L}}$ value indicates the shape of the isotherm to be irreversible $\left(R_{\mathrm{L}}=0\right)$, favourable $\left(0<R_{\mathrm{L}}<1\right)$, linear $\left(R_{\mathrm{L}}=0\right)$ or unfavorable $\left(R_{\mathrm{L}}>1\right) \cdot{ }^{37,39}$ The calculated $R_{\mathrm{L} 1}$ and $R_{\mathrm{L} 2}$ values are 0.031 and 0.137 . Both $R_{\mathrm{L}}$ values were between 0 and 1 , indicating that the adsorption of ester-containing pollutants on the activated carbon was favourable in this study. In addition, the Langmuir adsorption capacity of OAC $\left(q_{\mathrm{m} 1}\right)$ and 5th-RAC $\left(q_{\mathrm{m} 2}\right)$ are $162.08 \mathrm{mg} \mathrm{g}^{-1}$ and $129.02 \mathrm{mg} \mathrm{g}^{-1}$, respectively, where $q_{\mathrm{m} 2}$ has a $20.4 \%$ reduction in comparison to OAC. It was found that the adsorption capacity $\left(q_{\mathrm{m}}\right)$ of GAC for ester-containing pollutants decreased after MW regeneration, which could be explained by change in the textural properties (shown in Fig. 5a).

3.1.3 Adsorption kinetics. The OAC and RAC had rapid adsorption kinetics for ester-containing pollutants and their adsorption quickly reached equilibrium after approximately 30 min under different MW cycles (Fig. 3a). In comparison to the kinetic model of pseudo-first-order and IPD, the adsorption models of GAC at various MW cycles were in accordance with pseudo-second-order (shown in Table 4). The adsorption rate constant, $k_{2}\left(\mathrm{~g} \mathrm{mg}^{-1} \mathrm{~min}^{-1}\right)$ of RAC was increased with MW cycles. A similar result was reported by Liu et al., ${ }^{26}$ who also found that the adsorption rate of GAC after five cycles' reuse was higher than that of virgin GAC. However, Table 4 shows that the adsorption equilibrium $\left(q_{\mathrm{e}}\right)$ decreased with $\mathrm{MW}$ regeneration cycles, which could be ascribed to the change of textural properties of the GAC. It can also be seen that the $q_{\mathrm{e}}$ values obtained
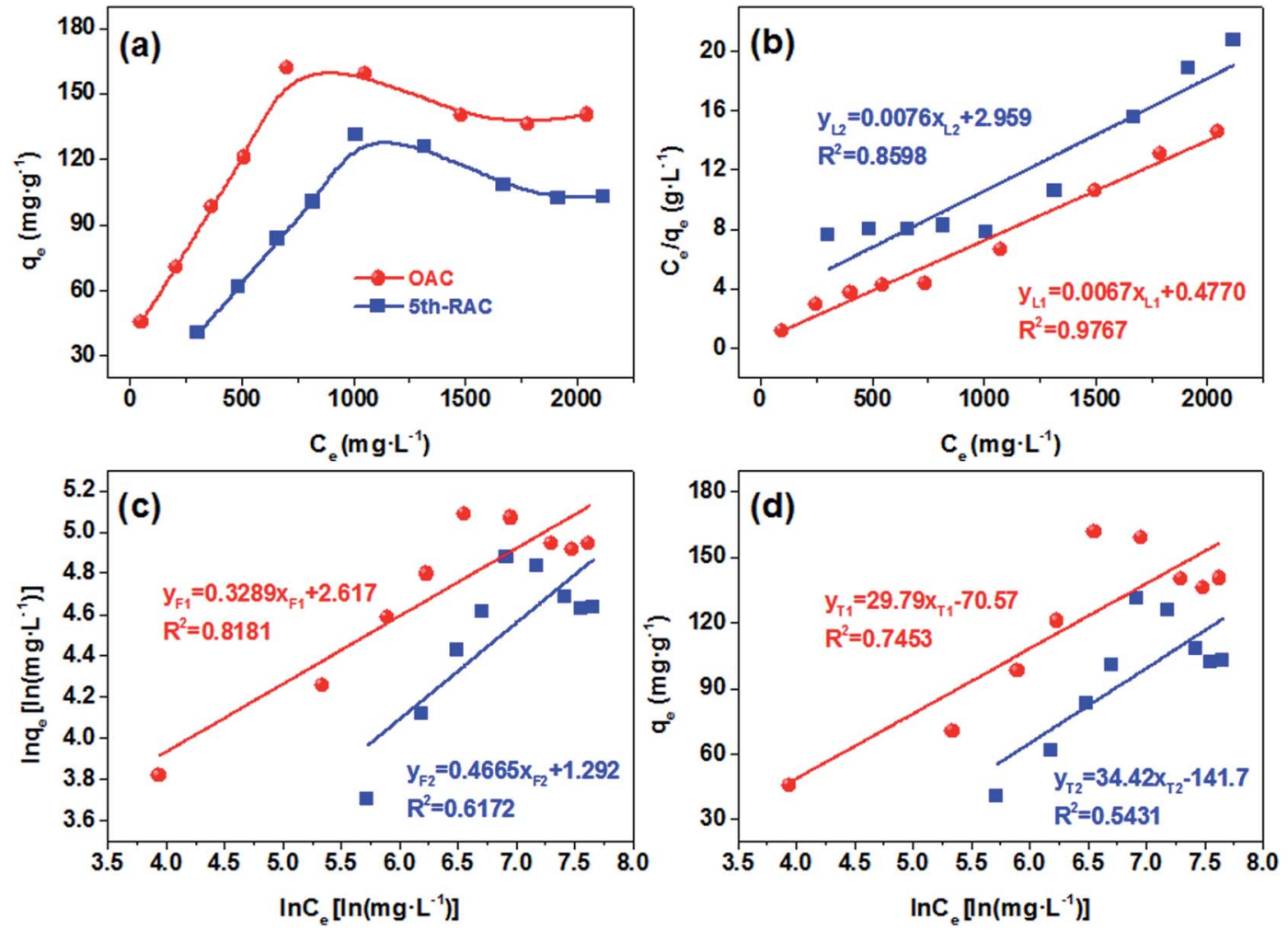

Fig. 2 (a) Equilibrium study on the adsorption of ester-containing pollutants onto OAC (original granular activated carbon) and 5th-RAC (5th granular regenerated activated carbon); (b) Langmuir isotherm; (c) Freundlich isotherm, and (d) Temkin isotherm for the adsorption of estercontaining pollutants onto OAC and 5th-RAC. 

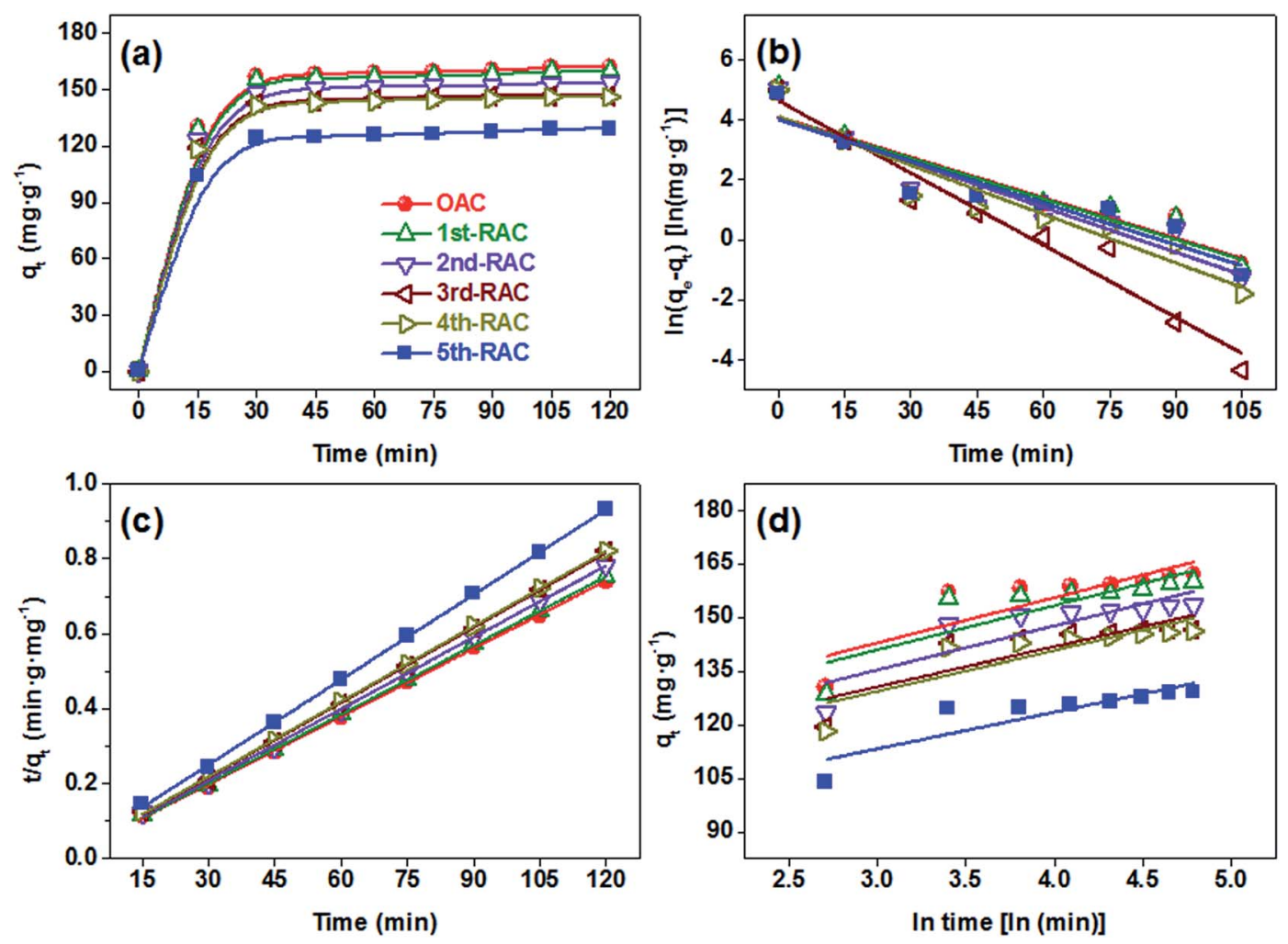

Fig. 3 (a) Effect of contact time on the adsorption of ester-containing pollutants by the original granular activated carbon (GAC); (b) pseudofirst-order; (c) pseudo-second-order, and (d) Elovich kinetic models for the adsorption of ester-containing pollutants by the GAC at various MW cycles.

Table 4 Comparison of the pseudo-first-order, pseudo-second-order and Elovich kinetic models for the adsorption of ester-containing pollutants by the GAC at various MW cycles

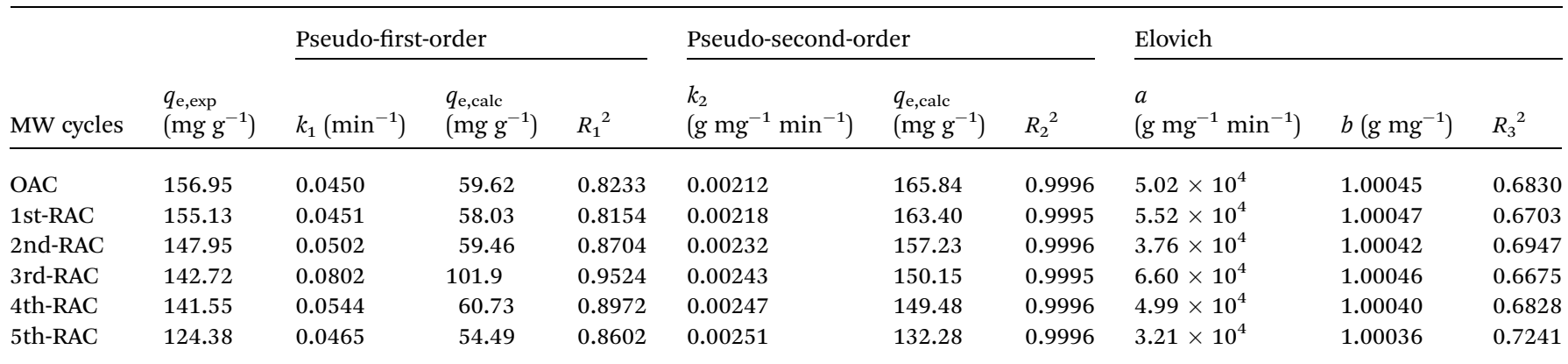

from the pseudo second-order kinetic model ( $\left.q_{\mathrm{e}, \mathrm{calc}}\right)$ of GAC for each of the MW cycles were similar to the obtained values from the experiment $\left(q_{\mathrm{e}, \exp }\right)$. Therefore, it can be ascertained that the pseudo second-order kinetic model is suitable to describe the adsorption of ester-containing pollutants by GAC at various MW cycles. That the pseudo-second-order model fits these data indicates that the rate of adsorption is dependent on the availability of the adsorption sites rather than the concentrations of adsorbate in the bulk solution.

3.1.4 Adsorption mechanism. The pseudo-first-order and pseudo-second order kinetic models do not explain the diffusion mechanism between solutes and particles. The intraparticle diffusion (IPD) mechanism describes whether the adsorption process followed the IPD or not. The curve-fitting plots of the IPD model are demonstrated in Fig. 4, and the IPD parameters can be seen from Table 5 . This plot can be divided into three portions: a sharp rise portion, a less steep portion and a plateau portion. The first linear step is due to diffusion through the mesopores of ester-containing pollutants, where the high value of the correlation coefficient $\left(R_{\mathrm{d} 1}{ }^{2}>\right.$ 0.9996) at various MW cycles indicates that IPD occurred. Moreover, the plot passed near the origin (as shown in Table 5), suggesting that IPD was the dominating rate-limiting mechanism. The adsorption rate constant, $k_{\mathrm{d} 1}\left(\mathrm{~g} \mathrm{mg}^{-1} \mathrm{~min}^{-1}\right)$ of RAC decreases with the MW cycle increment, which is the result of the destruction rate of mesopores to macropores being higher 


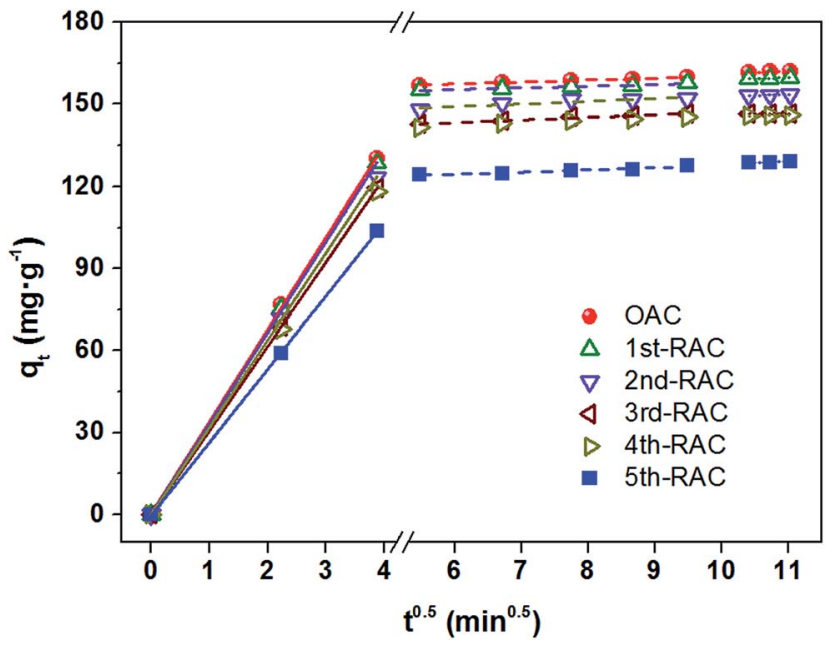

Fig. 4 Plot of an intraparticle diffusion (IPD) model for the adsorption of ester-containing pollutants onto the GAC at various MW cycles.

than the generation speed of mesopores from micropores (the mesopores of OAC and 5th-RAC are shown in Fig. 5d). The second linear step represents micropore diffusion. The regression is nearly linear for each MW cycle, but the high value of the intercept $\left(C_{\mathrm{d} 2}=140.5 \pm 12.2\right)$ indicates that, IPD was not the sole limiting mechanism. This is because the boundary layer thickness increased over adsorption time, and the external mass transfer resistance for ester-containing pollutants became stronger. The third region is the final equilibrium stage, still with a high correlation coefficient $\left(R_{\mathrm{d} 3}{ }^{2}=0.9945 \pm 0.004\right)$, indicating that IPD slowed as a result of the relative high concentrations of ester-containing pollutants in the wastewater. Moreover, the slope $\left(k_{\mathrm{di}}\right)$ of the three linear portions, decreased with increasing contact time under various MW cycles, indicating that the adsorption driving force was weaker and consequently that there was a reduced diffusion rate. ${ }^{40}$ As the ester-containing pollutant molecules diffuse into the inner structure of GAC, the pores become smaller. Therefore, the free path of molecules in the pore decreases and the molecules may also be blocked, which affects the adsorption rate.

\subsection{The change of textural properties of OAC and RAC}

The adsorption rate constant, $k_{2}\left(\mathrm{~g} \mathrm{mg}^{-1} \mathrm{~min}^{-1}\right)$ of RAC increased with an increase in the number of MW cycles. This is in contrast with adsorption models of GAC for the estercontaining pollutants. The change in RAC could be caused by a textural change in the regenerated GAC.

The adsorption capacity of GAC is reflected by the values calculated through application of the BET theorem. The $\mathrm{N}_{2}$ adsorption/desorption isotherms of OAC and 5th-RAC, as well as the DFT and HK pore size distributions were investigated to find out the influence of MW regeneration on GAC structure (shown in Fig. 5).

Fig. 5a shows the $\mathrm{N}_{2}$-adsorption/desorption isotherms of OAC and 5th-RAC. The adsorption/desorption isotherms of the two samples shows the first $\mathrm{N}_{2}$ uptake in the low-pressure region where $p / p_{0}<0.02$, indicating the presence of micropores (diameter $<2 \mathrm{~nm}$ ); there $\mathrm{N}_{2}$ uptake continues to increase after the low-pressure region, indicating the presence of a large amount of mesopores $(2 \mathrm{~nm}<$ diameter $<50 \mathrm{~nm})$. The 5 th-RAC presents a significant decrease in $\mathrm{N}_{2}$ adsorption/desorption capacity in comparison to OAC. Similar results were also derived in previous literature. ${ }^{26,41} \mathrm{~A}$ sharp decrease in the amount of adsorbed nitrogen was also reported after successive cycles of MW regeneration. Based on the nitrogen quantity adsorbed at different relative pressures, the main textural parameters of GAC were calculated (Fig. 5a). The BET surface area $\left(S_{\mathrm{BET}}\right)$ of 5 th-RAC was $892 \mathrm{~m}^{2} \mathrm{~g}^{-1}$, which was $79.6 \%$ of the OAC $\left(S_{\mathrm{BET}}\right.$ of $\left.1121 \mathrm{~m}^{2} \mathrm{~g}^{-1}\right)$. The total volume of 5th-RAC was lower than that of OAC. However, the total volume $\left(V_{\text {total }}\right)$ of 5 thRAC was still as high as $0.511 \mathrm{~cm}^{3} \mathrm{~g}^{-1}$, corresponding to a $24.4 \%$ destruction of the OAC $\left(V_{\text {total }}=0.676 \mathrm{~cm}^{3} \mathrm{~g}^{-1}\right)$.

The DFT curve of OAC and 5th-RAC reached a maximum at pore diameters of about $0.78 \mathrm{~nm}$ and $0.98 \mathrm{~nm}$, which shows that the maximum peak shifts after five MW regeneration cycles. This phenomenon was consistent despite the variation of $S_{\mathrm{BET}}$ and $V_{\text {total }}$. Further, the curve of the two samples also had two minor peaks represented by pores sizes of about 1.02 to 1.78 $\mathrm{nm}$, indicating the presence of supermicropores (diameter between 0.7 and $2 \mathrm{~nm}$ ). The $\mathrm{HK}$ and $\mathrm{BJH}$ pore size distribution curves of OAC and 5th-RAC are presented in Fig. $5 \mathrm{c}$ and d. The HK curve of two samples had a maximum derivative micropore volume ( $\mathrm{d} V_{\text {micro }}$ ) value of $0.099 \mathrm{~cm}^{3} \mathrm{~g}^{-1}$ and $0.075 \mathrm{~cm}^{3} \mathrm{~g}^{-1}$ at $0.56 \mathrm{~nm}$ and $0.61 \mathrm{~nm}$, respectively, as corresponding to the $V_{\text {micro }}$ of 0.471 and $0.363 \mathrm{~cm}^{3} \mathrm{~g}^{-1}$. It was revealed that the 5 thRAC still had potential for the adsorption of micromolecular organics from aqueous phase (diameter between 0.4 and 0.9 $\mathrm{nm})$. This conclusion is consistent with the GAC adsorption

Table 5 Parameters of an intraparticle diffusion (IPD) model for the adsorption of ester-containing pollutants onto the GAC at various MW cycles

\begin{tabular}{|c|c|c|c|c|c|c|c|c|c|}
\hline MW cycles & $\begin{array}{l}k_{\mathrm{d} 1} \\
\left(\mathrm{~g} \mathrm{mg}^{-1} \min ^{-0.5}\right)\end{array}$ & $C_{1}$ & $R_{\mathrm{d} 1}^{2}$ & $\begin{array}{l}k_{\mathrm{d} 2} \\
\left(\mathrm{~g} \mathrm{mg} \mathrm{min}^{-1} \min ^{-0.5}\right)\end{array}$ & $C_{2}$ & $R_{\mathrm{d} 2}^{2}$ & $\begin{array}{l}k_{\mathrm{d} 3} \\
\left(\mathrm{~g} \mathrm{mg}^{-1} \min ^{-0.5}\right)\end{array}$ & $C_{3}$ & $R_{\mathrm{d} 3}^{2}$ \\
\hline OAC & 33.71 & 0.4193 & 0.99965 & 0.7049 & 153.2 & 0.98305 & 0.6131 & 155.4 & 0.99145 \\
\hline 2nd-RAC & 31.90 & 0.1398 & 0.99996 & 0.9862 & 143.2 & 0.82952 & 0.3976 & 149.1 & 0.99706 \\
\hline 3rd-RAC & 30.82 & 0.0000 & 0.99999 & 0.9351 & 137.8 & 0.96482 & 0.0186 & 146.3 & 0.99981 \\
\hline 4th-RAC & 30.50 & -0.1398 & 0.99995 & 0.8688 & 137.0 & 0.96272 & 0.2353 & 143.4 & 0.99289 \\
\hline
\end{tabular}



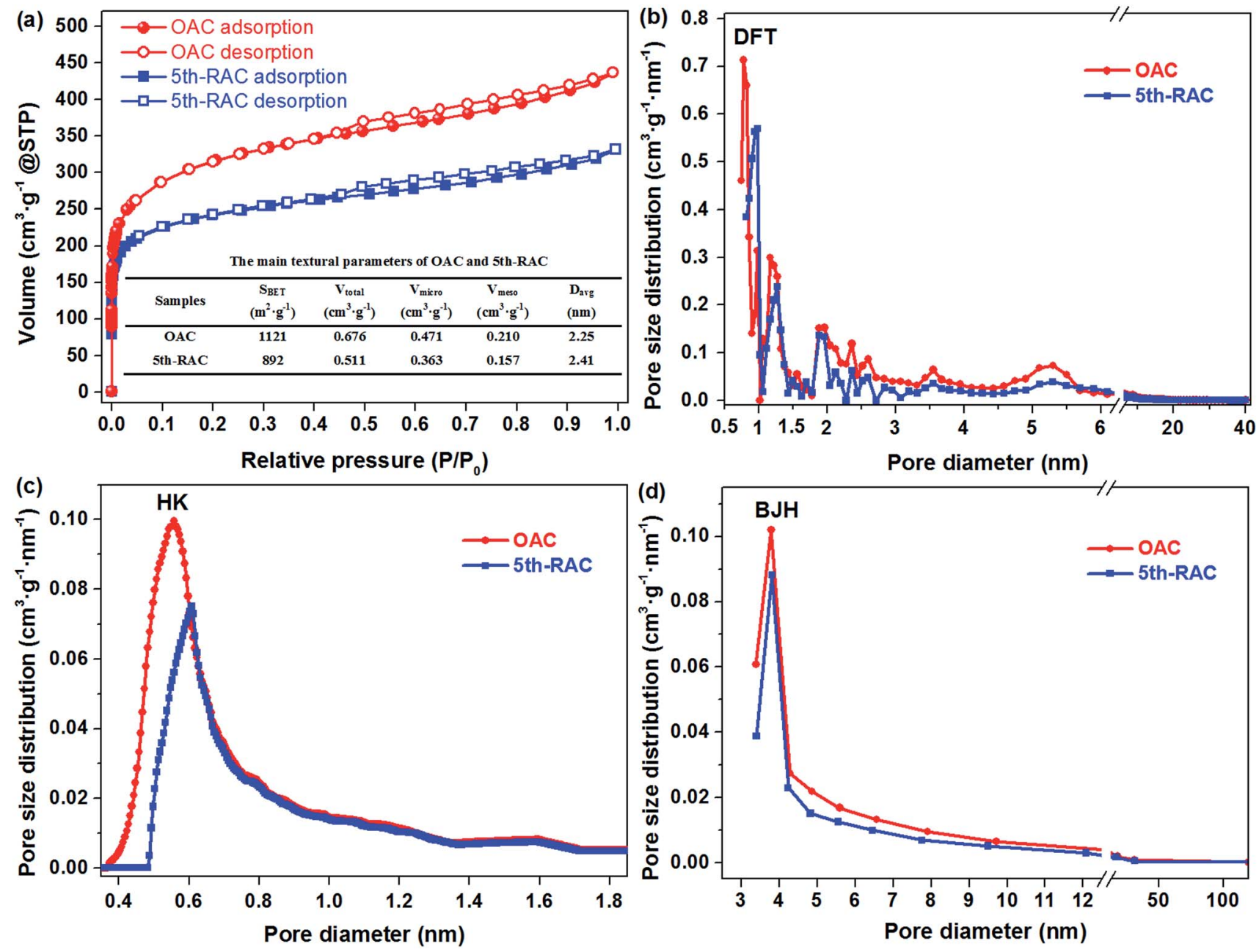

Fig. 5 (a) $\mathrm{N}_{2}$-adsorption/desorption isotherms and main textural parameters (inset); (b) DFT pore size distribution; (c) HK pore size distribution and (d) BJH pore size distribution of original granular activated carbon (OAC) and 5th regenerated granular activated carbon (5th-RAC).

mechanism for ester-containing pollutants, where the intercept $\left(C_{2}\right)$ in the second linear step of IPD decreased slightly (shown in Table 5). Moreover, the BJH curve of OAC and 5th-RAC reached a maximum at $3.79 \mathrm{~nm}$ and $3.81 \mathrm{~nm}$ respectively, corresponding to mesopore volumes $\left(V_{\text {meso }}\right)$ of $0.471 \mathrm{~cm}^{3} \mathrm{~g}^{-1}$ and $0.363 \mathrm{~cm}^{3} \mathrm{~g}^{-1}$, indicating that the mesopores can provide channels for some macromolecular adsorbates. It can also be concluded that the decreasing $V_{\text {meso }}$ caused the decrement of the diffusion rate constant, $k_{\mathrm{d} 1}\left(\mathrm{~g} \mathrm{mg}^{-1} \mathrm{~min}^{-1}\right)$, where the $k_{\mathrm{d} 1}$ of OAC and 5th-RAC were $33.71 \mathrm{~g} \mathrm{mg}^{-1} \mathrm{~min}^{-0.5}$ and $26.78 \mathrm{~g} \mathrm{mg}^{-1}$ $\min ^{-0.5}$ (shown in Table 5).

Therefore, though the adsorption rate constant of the pseudo-second-order model of RAC, $k_{2}\left(\mathrm{~g} \mathrm{mg} \mathrm{min}^{-1}\right)$, increased through MW cycles, the adsorption capacity $\left(q_{\mathrm{m}}\right)$ decreased due to the decreasing $S_{\mathrm{BET}}$ and the $k_{\mathrm{d} 1}\left(\mathrm{~g} \mathrm{mg}^{-1}\right.$ $\left.\min ^{-1}\right)$.

\subsection{The mechanism of MW regeneration}

In order to investigate the mechanism of the MW regeneration process, the surface functional groups and TG-DTG of the GAC samples were investigated.
3.3.1 Surface functional groups. FTIR spectra recorded for the GAC samples and the variation of groups over MW cycles can be seen in Fig. 6 . The functional groups identified from the FTIR spectra are given in Table 6. Moreover, the structural formula of the surface function groups of GAC is shown in Fig. S1.†

For OAC, the band centred at $3429 \mathrm{~cm}^{-1}$ indicates the presence of-OH functional groups; two weak bands at $2922 \mathrm{~cm}^{-1}$ and $2854 \mathrm{~cm}^{-1}$ can be assigned to asymmetric $\mathrm{C}-\mathrm{H}$ and symmetric $\mathrm{C}-\mathrm{H}$ bands, respectively; the band at $2360 \mathrm{~cm}^{-1}$ was attributed to $\mathrm{C}=\mathrm{O}$ asymmetric stretching vibration in $\mathrm{CO}_{2}$; the intense band occurring at $1117 \mathrm{~cm}^{-1}$ demonstrated the $\mathrm{C}-\mathrm{O}$ asymmetric stretching. SAC and RAC had similar functional groups to OAC, except for the absorption band at $1635 \mathrm{~cm}^{-1}$ and $1587 \mathrm{~cm}^{-1}$. The absorption peak at $1635 \mathrm{~cm}^{-1}$ of OAC was transferred to 1587 $\mathrm{cm}^{-1}$ in SAC after the adsorption stage, which might be ascribed to variation in their surface groups. Compared with OAC, the RAC peak at $1587 \mathrm{~cm}^{-1}$ represented the in-plane skeletal vibrations in aromatic rings. This could be explained by that the phenolic hydroxyl groups $(\mathrm{PhOH})$ on the surface of OAC increasing with the number of MW cycles (Fig. 6b). 

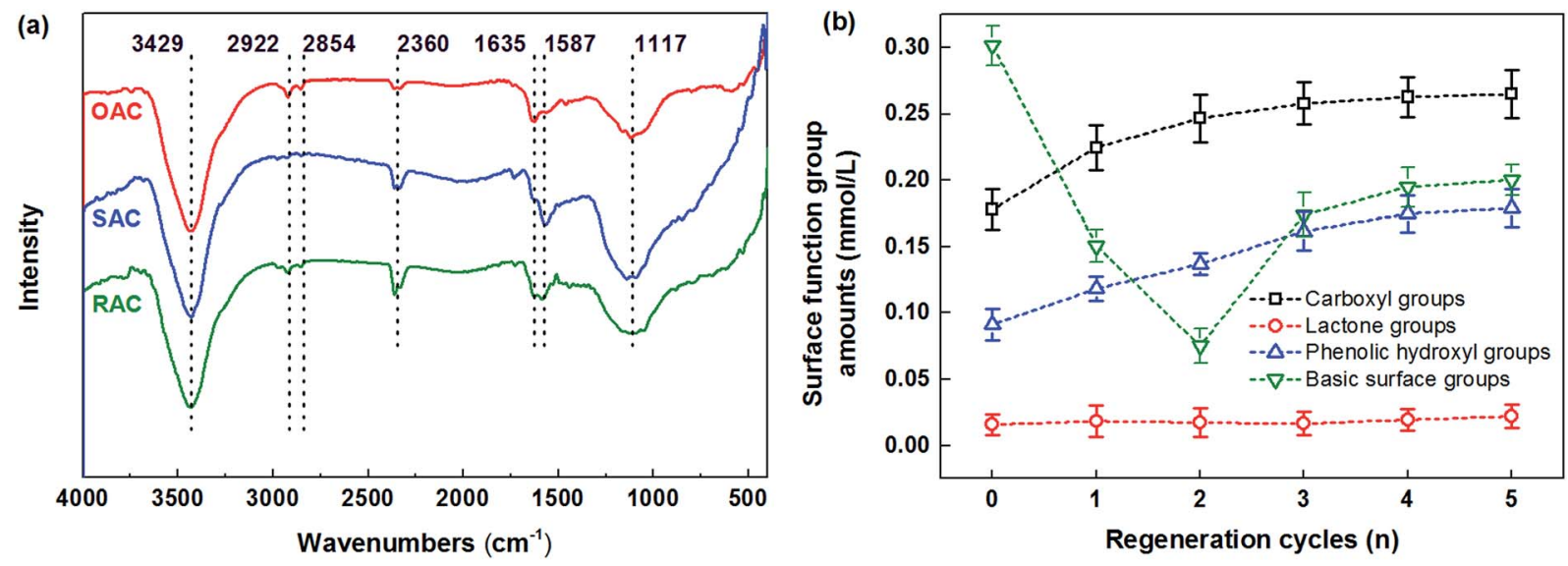

Fig. 6 (a) FTIR spectrum for activated carbon of original granular activated carbon (OAC), saturated granular activated carbon (SAC), and regenerated granular activated carbon for the first regeneration cycle (RAC); (b) variation in the amounts of different surface function group with the regeneration cycles. Error bars in (b) represent the standard deviation of three samples each from an independent run of the reactor.

Table 6 The main FTIR bands for OAC, SAC and RAC

\begin{tabular}{lll}
\hline Wavenumber $\left(\mathrm{cm}^{-1}\right)$ & Peak assignment & Description \\
\hline 3429 & $-\mathrm{OH}$ stretching & Phenols and alcohols \\
2922 & Aliphatic $\mathrm{CH}_{3}$ stretching & Alkanes \\
2854 & Aliphatic $\mathrm{CH}_{2}$ stretching & Alkanes \\
2360 & $\mathrm{C}=\mathrm{O}$ asymmetric stretching & $\mathrm{CO}_{2}$ \\
1635 & $\mathrm{C}=\mathrm{O}$ stretching & (Acid, aldehyde and ketone) \\
1587 & In-plane skeletal vibrations of $\mathrm{C}=\mathrm{C}$ in aromatic rings & - \\
1117 & $\mathrm{C}-\mathrm{O}$ stretching & Ester
\end{tabular}

The peaks at $1117 \mathrm{~cm}^{-1}$ in SAC was apparently sharper than that in OAC. The differences between the FTIR results of SAC and OAC demonstrate that ester containing organic matter was absorbed onto the OAC. The $1117 \mathrm{~cm}^{-1}$ peak of RAC was slightly sharper than that of OAC, which could have been caused by an increase in carboxyl groups on the surface of OAC, though adsorbed ester-containing contaminants were removed during MW regeneration (Fig. 6a). In addition, carboxyl groups and phenolic hydroxyl groups $(\mathrm{PhOH})$ on the surface of OAC increased with the increase in regeneration cycles (Fig. 6b). The variation of lactone groups was stable throughout all regeneration cycles. The amount of basic surface groups rapidly decreased and then gradually increased during the five MW regeneration cycles. $\mathrm{pH}$ in wastewater decreases with a decrease in the amount of basic surface groups, and lower $\mathrm{pH}$ has a positive influence on adsorption due to the enhancement of the hydrophilic properties of GAC. ${ }^{42-44}$ Franz et al. ${ }^{45}$ reported that the adsorption of phenol by activated carbon at $\mathrm{pH}$ of 3 was significantly higher than that at a $\mathrm{pH}$ of 11.0. Furthermore, the regeneration efficiency had a negative correlation with the amount of basic surface groups for the last three MW regeneration cycles, which decreased with the increase in basic surface groups. A similar phenomenon was also derived by Liu et al. ${ }^{29}$ who reported that regeneration efficiency decreased for the regenerated GAC while the surface basicity increased instead.
3.3.2 TG-DTG. The TG and derivative thermogravimetric (DTG) curves of OAC and SAC are shown in Fig. 7.

The weight loss of OAC and SAC below $100^{\circ} \mathrm{C}$ was attributed to the loss of adsorbed water. The weight loss of OAC and SAC from 300 to $900{ }^{\circ} \mathrm{C}$ were similar. Compared with OAC, the weight loss of SAC between 120 and $260{ }^{\circ} \mathrm{C}$ may have been caused by the decomposition of small ester organic molecules,

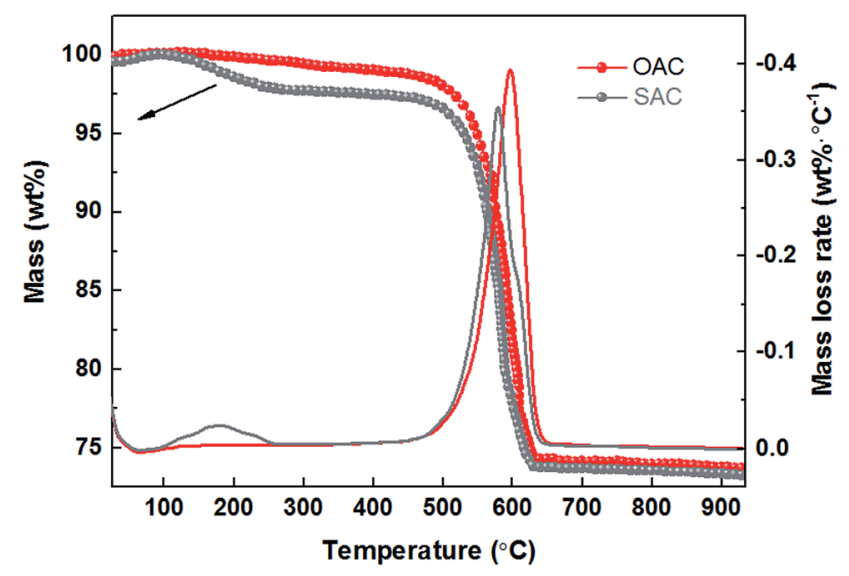

Fig. 7 The thermogravimetric (TG) and derivative thermogravimetric (DTG) curves of original granular activated carbon (OAC) and saturated granular activated carbon (SAC). 
such as DMC, CEM, DC, and EC, which were adsorbed in the adsorption stage. The result shows that the ester organic pollutants in SAC were easily regenerated at lower temperatures. This may have been because the binding forces between the adsorption sites of the GAC and the ester contaminants were weak and easily destroyed by the absorption of MW energy during MW regeneration.

\section{Conclusion}

This study provides an understanding of the mechanism of a GAC adsorption/MW irradiation process for the treatment of ester-containing wastewater from a LIB factory. The results show that the adsorption isotherms and kinetics are in accordance with the Langmuir isotherm and pseudo second-order kinetic model. The adsorption rate constant, $k_{2}\left(\mathrm{~g} \mathrm{mg}^{-1}\right.$ $\min ^{-1}$ ) of RAC increased with MW regeneration cycles, the adsorption capacity $\left(q_{\mathrm{m}}\right)$ decreased where the $q_{\mathrm{m}}$ of 5 th-GAC had a $20.4 \%$ reduction in comparison to the determined OAC, which could be explained by a change in GAC textural properties. FTIR analysis showed that the GAC adsorption/MW process for the ester-containing pollutants mainly occurred at the peak of $1117 \mathrm{~cm}^{-1}$. Based on TG-DTG analysis, the weight loss of SAC took place between 120 and $260{ }^{\circ} \mathrm{C}$, which indicates that the ester contaminants that polluted GAC can be easily regenerated by MW.

\section{Abbreviations}

$\begin{array}{ll}\text { GAC } & \text { Granular activated carbon } \\ \text { OAC } & \text { Original GAC } \\ \text { SAC } & \text { Saturated GAC } \\ \text { RAC } & \text { Regenerated GAC } \\ R_{\mathrm{E}} & \text { Regeneration efficiency } \\ R_{\mathrm{S}} & \text { Regeneration loss } \\ \text { MW } & \text { Microwave } \\ \text { LIB } & \text { Lithium-ion battery } \\ \text { DMC } & \text { Dimethyl carbonate } \\ \text { CEM } & \text { Carbonic acid ethyl methylester } \\ \text { DC } & \text { Diethyl carbonate } \\ \text { EC } & \text { Ethylene carbonate } \\ \text { NMP } & N \text {-Methylpyrrolidone } \\ \text { LiPF } & \text { Lithium hexafluoro phosphate } \\ \text { IPD } & \text { Intraparticle diffusion }\end{array}$

\section{Acknowledgements}

The authors gratefully acknowledge the financial support of the National Environmental Protection Public Welfare Science and Technology Research Program of China (Grant No. 201309023).

\section{References}

1 H. Cao, X. Wang, H. Gu, J. Liu, L. Luan, W. Liu, Y. Wang and Z. Guo, RSC Adv., 2015, 5, 34566-34571.
2 X. Li, H. Gu, J. Liu, H. Wei, S. Qiu, Y. Fu, H. Lv, G. Lu, Y. Wang and Z. Guo, RSC Adv., 2015, 5, 7237-7244.

3 X. Zeng, J. Li and N. Singh, Crit. Rev. Environ. Sci. Technol., 2014, 44, 1129-1165.

4 S. Castillo, F. Ansart, C. Laberty-Robert and J. Portal, J. Power Sources, 2002, 112, 247-254.

5 S. Qiu, H. Gu, G. Lu, J. Liu, X. Li, Y. Fu, X. Yan, C. Hu and Z. Guo, RSC Adv., 2015, 5, 46509-46516.

6 J. F. Paulino, N. G. Busnardo and J. C. Afonso, J. Hazard. Mater., 2008, 150, 843-849.

7 L. Sun and K. Qiu, J. Hazard. Mater., 2011, 194, 378-384.

8 L. Chen, X. Tang, Y. Zhang, L. Li, Z. Zeng and Y. Zhang, Hydrometallurgy, 2011, 108, 80-86.

9 L. Pietrelli, B. Bellomo, D. Fontana and M. Montereali, Waste Manag., 2005, 25, 221-226.

10 L. Li, J. Ge, R. Chen, F. Wu, S. Chen and X. Zhang, Waste Manag., 2010, 30, 2615-2621.

11 L. Li, J. Ge, F. Wu, R. Chen, S. Chen and B. Wu, J. Hazard. Mater., 2010, 176, 288-293.

12 Z. Zhang, T. Zheng, X. Wang, Z. Wang, Y. Ma and Q. Wang, China Environ. Sci., 2014, 34, 644-649.

13 K. Y. Foo and B. H. Hameed, J. Hazard. Mater., 2009, 171, 5460.

14 N. Lesage, M. Sperandio and C. Cabassud, Chem. Eng. Process., 2008, 47, 303-307.

15 P. M. Alvarez, F. J. Beltran, V. Gomez-Serrano, J. Jaramillo and E. M. Rodriguez, Water Res., 2004, 38, 2155-2165.

16 C. Chiu, K. Hristovski, S. Huling and P. Westerhoff, Water Res., 2013, 47, 1596-1603.

17 D. Guo, Q. Shi, B. He and X. Yuan, J. Hazard. Mater., 2011, 186, 1788-1793.

18 K. Y. Foo and B. H. Hameed, Chem. Eng. J., 2012, 193, 404409.

19 Ö. Aktaş and F. Çeçen, Bioresour. Technol., 2009, 100, 46044610.

20 Z. Zhang, W. Qu, J. Peng, L. Zhang, X. Ma, Z. Zhang and W. Li, Desalination, 2009, 249, 247-252.

21 F. K. Yuen and B. H. Hameed, Adv. Colloid Interface Sci., 2009, 149, 19-27.

22 K. Y. Foo and B. H. Hameed, Bioresour. Technol., 2012, 119, 234-240.

23 H. Wei, C. He, J. Liu, H. Gu, Y. Wang, X. Yan, J. Guo, D. Ding, N. Z. Shen and X. Wang, Polymer, 2015, 67, 192-199.

24 H. Gu, D. Ding, P. Sameer, J. Guo, N. Yerra, Y. Huang, Z. Luo, T. C. Ho, N. Haldolaarachchige and D. P. Young, ECS Solid State Lett., 2013, 2, M65-M68.

25 C. O. Ania, J. B. Parra, J. A. Menendez and J. J. Pis, Water Res., 2007, 41, 3299-3306.

26 X. Liu, G. Yu and W. Han, J. Hazard. Mater., 2007, 147, 746751.

27 H. Mao, D. Zhou, Z. Hashisho, S. Wang, H. Chen and H. H. Wang, J. Ind. Eng. Chem., 2015, 21, 516-525.

28 S. Deng, P. Wang, G. Zhang and Y. Dou, J. Hazard. Mater., 2016, 307, 64-72.

29 Q. S. Liu, P. Wang, S. S. Zhao and W. Zhang, J. Chem. Technol. Biotechnol., 2012, 87, 1004-1009. 
30 F. S. Wei, W. Q. Qi, Z. G. Sun, Y. R. Huang and Y. W. Shen, in Water and wastewater monitoring and analysis method, China Environmental Science Press, Beijing, 2002.

31 H. P. Boehm, Carbon, 1994, 32, 759-769.

32 P. K. Malik, J. Hazard. Mater., 2004, 113, 81-88.

33 A. Behnamfard and M. M. Salarirad, J. Hazard. Mater., 2009, 170, 127-133.

34 I. Tan, A. L. Ahmad and B. H. Hameed, J. Hazard. Mater., 2009, 164, 473-482.

35 W. J. Weber and J. C. Morris, J. Sanit. Eng. Div., Am. Soc. Civ. Eng., 1963, 89, 31-60.

36 I. Langmuir, J. Am. Chem. Soc., 1916, 38, 2221-2295.

37 K. Y. Foo and B. H. Hameed, Chem Eng J, 2010, 156, 2-10.

38 T. W. Weber and R. K. Chakravorti, AIChE J., 1974, 20, 228238.
39 P. K. Malik, J. Hazard. Mater., 2004, 113, 81-88.

40 Y. Ma, Q. Wang, X. Wang, X. Sun and X. Wang, J. Porous Mater., 2015, 22, 157-169.

41 C. O. Ania, J. B. Parra, J. A. Menendez and J. J. Pis, Microporous Mesoporous Mater., 2005, 85, 7-15.

42 P. Faria, J. Orfao and M. Pereira, Water Res., 2004, 38, 20432052.

43 S. Babel and T. A. Kurniawan, J. Hazard. Mater., 2003, 97, 219-243.

44 M. Kobya, E. Demirbas, E. Senturk and M. Ince, Bioresour. Technol., 2005, 96, 1518-1521.

45 M. Franz, H. A. Arafat and N. G. Pinto, Carbon, 2000, 38, 1807-1819. 